\title{
Reply to the Discussion by Arroglu et al. on "Estimating the Strength of Jointed Rock Masses" by Zhang, DOI 10.1007/s00603-009-0065-x
}

\author{
Lianyang Zhang
}

Published online: 3 May 2011

(C) Springer-Verlag 2011

The author would like to express his thanks to the discussers for their interest in the paper and their effort to provide the community with detailed and constructive comments. The discussers' comments and concerns are addressed below.

It is clearly stated in the paper that "RQD is only one of the many factors that affect the strength of jointed rock masses." The discussers correctly re-emphasized this point and discussed the effect of joint conditions on the rock mass to intact rock strength ratio $\left(\sigma_{\mathrm{cm}} / \sigma_{\mathrm{c}}\right)$. However, as the discussers correctly stated again in the discussion, in many cases, RQD is the only parameter available for describing rock discontinuities. So, it is extremely important to develop a method for estimation of rock mass strength when only RQD is available. The new $\sigma_{\mathrm{cm}} / \sigma_{\mathrm{c}}$ versus RQD relation developed in the paper provides such a method for a first hand estimation. When RQD and the joint condition information are available, the $\sigma_{\mathrm{cm}} / \sigma_{\mathrm{c}}$ versus RQD relation can be used together with other empirical methods considering joint condition to evaluate the rock mass strength.

The empirical methods including the new $\sigma_{\mathrm{cm}} / \sigma_{\mathrm{c}}$ versus RQD relation developed in the paper are for estimating the strength of a jointed rock mass which can be treated as an equivalent continuum in analysis. As stated in the paper, the structure being analyzed must be much larger than the rock blocks formed by the discontinuities in order for the rock mass to be treated as an equivalent continuum. The effect of tunnel span on the strength of rock masses, as

\footnotetext{
L. Zhang $(\bowtie)$

Department of Civil Engineering and Engineering Mechanics,

University of Arizona, Tucson, AZ, USA

e-mail: lyzhang@email.arizona.edu
}

described by the discussers, is essentially the scale effect as emphasized in the paper.

Disturbance caused by excavation will obviously affect the strength of rock masses. The effect of disturbance can be considered using a disturbance factor as done by Hoek et al. (2002) or modifying the parameter for describing the discontinuities. To use the new $\sigma_{\mathrm{cm}} / \sigma_{\mathrm{c}}$ versus RQD relation to estimate the strength of disturbed rock masses, the modified RQD should be utilized.

The discussers also discussed the effect of loading time on the strength of rock masses. It needs to be noted that the loading time also affects the strength of intact rock. So, if an empirical relation uses the strength ratio $\sigma_{\mathrm{cm}} / \sigma_{\mathrm{c}}$ and the intact rock strength $\sigma_{\mathrm{c}}$ at the corresponding loading time is used, the effect of loading time on the rock mass strength $\sigma_{\mathrm{cm}}$ will be (partially) considered. Besides the loading time, loading rate will also affect the strength of both intact rock and rock mass (Kobayashi 1970; Cristescu and Hunsche 1998).

\section{References}

Cristescu ND, Hunsche U (1998) Time effects in rock mechanics. Wiley, New York

Hoek E, Carranza-Torres C, Corkum B (2002) Hoek-Brown failure criterion-2002 edition. In: Proceedings of 5th North American rock mechanical symposium and 17th tunneling association of Canada conference: NARMS-TAC 2002. Mining Innovation and Technology, Toronto, pp 267-273

Kobayashi R (1970) On the mechanical behavior of rocks under various loading rates. Rock Mech Jpn 1:56-58 